\title{
Populismo y ciclos de conflictividad política en el Ecuador. Una entrevista con Valeria Coronel ${ }^{*}$
}

\section{Introducción}

$\mathrm{L}$ a siguiente entrevista está orientada a brindar una lectura del populismo en el Ecuador a partir del trabajo de la historiadora Valeria Coronel. Contrario a las consideraciones del populismo como distorsión democrática, las investigaciones de Valeria Coronel permiten pensar el populismo dentro de los ciclos políticos en los cuales se condensan luchas democráticas que involucran una heterogeneidad de actores sociales. La entrevista fue realizada el 3 de junio de 2019.

\footnotetext{
* Valeria Coronel es docente-investigadora en la Facultad Latinoamericana de Ciencias Sociales (FLACSOEcuador). Obtuvo el Doctorado en Historia en la Universidad de Nueva York (NYU). Su investigación se relaciona con la transición del estado oligárquico al estado nacional en la región andina, y formas de movilización e integración del campesinado indígena en los partidos políticos entre el siglo XIX y XX. También ha estudiado la trayectoria de la formación de derechos sociales a partir del análisis del conflicto social y las fronteras de clase y etnicidad en el Ecuador. Entre sus publicaciones destacan: Izquierdas, sindicatos y militares en la disputa por la tendencia democrática del Ecuador de entreguerras (1925-1945)' (2018), La revolución gloriosa: una relectura desde la estrategia de la hegemonía de la izquierda de entreguerras' (2016), Justicia laboral y formación del Estado como contraparte ante el capital transnacional en Ecuador 1927-1938' (2013), 'La fragua de la voz: cartas sobre revolución, subjetividad y cultura nacional-popular' (2012). Su libro La última guerra del siglo de las luces: Revolución Liberal y formación del estado nacional en el Ecuador (1880-1926)' está próximo a publicarse. Su publicaciones más recientes son 'The Twentieth Century Ecuadorian Left: Mobilization Of Republican Democracy, Class Struggle And State Formation during the Global Crisis', en Giulia Bassi (ed.) 'Words of Power, the Power of Words: the Twentieth-Century Communist Discourse in International Perspective: Trieste EUT, y 'Sobre campos discursivos y campos de fuerza en la formación nacional. Diálogo con Guillermo Bustos' en Procesos: revista ecuatoriana de historia, n. 49 185-189. (enero-junio 2019), Quito: Universidad Andina Simón Bolívar, Corporación Editora Nacional, Taller de Estudios Históricos.

** Candidato a Ph.D. en Sociología por la Universidad de Massachussets-Amherst. Profesor titular agregado de la Escuela de Sociología de la Pontificia Universidad Católica del Ecuador. Co-director editorial de la revista Theorein.

*** Licenciado en sociología con mención en Desarrollo (Pontificia Universidad Católica del Ecuador). Coordinador editorial de la revista Theorein.
} 
P: En relación con el contexto de tu trabajo, ¿cuáles son las experiencias de lo nacional popular que has estudiado en Ecuador y cómo se conectan con el populismo?

Valeria Coronel: Al referirme al concepto 'populismo', no pienso en un sistema social ni en un tipo de liderazgo con ' $\mathrm{x}$ ' $\mathrm{o}$ ' $\mathrm{y}$ ' características esquemáticas. Me interesa el concepto 'populismo' en la medida en que, en esos términos, se denominó y se debatió sobre un momento de la acción colectiva que reactivó el lenguaje de la soberanía popular y dio nuevo aliento a la formación del Estado Nacional en América Latina en el marco de crisis globales.

El periodo clásico se encuentra entre las décadas de 1920 y la segunda postguerra. Como respuesta a la crisis, en los años veinte se produjo en varios países una reactivación de la movilización social que mostró el límite de los partidos, y exigió la popularización de las promesas democráticas, generando un nuevo ciclo de combate que no se había dado desde el fin de las guerras republicanas del siglo XIX en la mayoría de los países latinoamericanos. Como resultado de las guerras del siglo XIX, el continente vivió experiencias de poder relativamente consolidado. Debido al éxito del republicanismo liberal, -en el caso ecuatoriano-, o del conservadurismo -o de un pacto interpartidista, como el de la Colombia de Nuñez-, entre finales del siglo XIX y la segunda década del siglo XX, aproximadamente, la conflictividad social se expresó/contuvo a través de vehículos institucionales y la fuerza. Es decir, antes de la crisis de mediados de los veinte, y del ciclo de reemergencia de lo popular y de reforma estatal que le siguió a tal crisis (que se conocen como 'populismos clásicos'), hubo una pausa de un modo de combate social que se podría describir como universal, público, constituyente e instituyente. Precisamente, este renacimiento de la movilización popular soberanista e instituyente es lo que se observa en mi trabajo sobre el problema nacional popular y los populismos clásicos latinoamericanos, que ocurren en momentos distintos, en base a trayectorias y lenguajes políticos diversos, incluso con modos de conducción política distintos. De las milicias del siglo XIX, vemos un salto a la movilización de 
organizaciones civiles que se van configurando en nuevas formas de organización política popular, que identifican sus condiciones de opresión, de desposesión, en registros como 'clase', 'raza' y 'pueblo', presentando así sus argumentos de una forma tal que aparecen como problemas relativos a la soberanía en conjunto, de importancia primera para la comunidad política, para la sobrevivencia de las repúblicas democráticas.

Este combate no se resolvió a través de los regímenes existentes cuya hegemonía fue sometida a tensiones que produjeron un salto histórico. Para resolver, redimir o integrar esas demandas y esas contradicciones -incluso esa fuerza exhibida por la sociedad-, se produjo una transformación del conjunto del campo político.

Esto no sucedió solamente por el nuevo proceso de movilización que se producía en cada sociedad de forma regional o aisladamente, sino también por el surgimiento, la potenciación y promoción de las organizaciones continentales e internacionales. La historia del populismo clásico latinoamericano es parte de la historia de la izquierda del siglo XX, precisamente en lugares en los que no fue devastada, como en Europa, y donde tomó rumbos propios al configurar formas de poder. En la periferia del mundo imperialista, la izquierda tuvo un impacto importante en la orientación de las reformas políticas que tuvieron lugar durante la crisis mundial: el mismo caso de Rusia puede ser visto así, por fuera de toda narrativa teleológica, pero es también es el caso de China, así como de aquellos países latinoamericanos como el México de Cárdenas, el Ecuador de la revolución juliana y 'la Gloriosa', Cuba y Bolivia en los años treinta, y los más conocidos casos de Argentina y Brasil populistas.

En este contexto sucedieron dos cosas de manera relacionada. La primera de ellas es la que normalmente se identifica como 'populismo', que no es más que una propuesta de renovación hegemónica que incluyó la transformación del Estado. El Estado tuvo que renovarse para asumir la conflictividad y, por lo tanto, hubo un proceso de construcción institucional que complejizó el modelo anterior de República, desarrollando, sobre todo, las condiciones materiales para 
el ejercicio de los derechos políticos. Esto es lo que con algunas colegas, como Luciana Cadahia, Soledad Stoessel, Ailynn Torres, entre otras, reconocemos como la razón republicana democrática de la institucionalización 'populista': algo visible en las agencias redistributivas, las de los derechos sociales, las de la representación corporativa popular en los poderes del estado, entre otros. En segundo lugar, hubo una transformación muy importante de la esfera pública porque, de una forma u otra, se expandió la gran industria de la imprenta hacia lugares de producción y apropiación que excedieron lo conocido. Lo popular entró así no solo en representaciones sino en usos del lenguaje y, más allá del asalto popular en forma y fondo de la circulación impresa, a través de distintas mediaciones, se instaló en la sensibilidad donde era impensable lo nacional sin la voz disruptiva de lo popular.

Ahora bien, a estos dos procesos se suman estilos de gobierno. De hecho, en este ciclo hay estilos de gobierno de tipo presidencialista/carismático -objeto favorito de los críticos del populismo en tanto les parece un signo de reducción del campo democrático-, y hay otros casos en los que estas figuras de liderazgo que articulan las masas a la política del Estado son más frágiles. Pero, por otro lado, existen mediaciones institucionales y la agencia de la burocracia militante, como fue el caso de México, Ecuador y Bolivia durante dos décadas de desarrollo del derecho social en torno a la tierra y el trabajo.

Un ejemplo de esto último, he argumentado, es el caso ecuatoriano pues tiene todos los ingredientes: un ciclo de combate, un ciclo de organización, una reforma estatal hacia nociones de Estado de bienestar y orientaciones de lo popular, una noción de ciudadanía y economía, una transformación de la esfera pública. Estos factores se dan en el Ecuador, pero sin una figura carismática que exprese todo este momento. Ciertamente existe una figura carismática, pero es un error en la historiografía ecuatoriana identificar todo el proceso con el surgimiento de Velasco Ibarra. El Velasco Ibarra de los treinta y cuarenta se entiende mejor como un actor atento a la transformación de la derecha: dispuesto a competir en la conducción de este proceso en el que el liberalismo social se enfrenta con la izquierda -0 , mejor dicho, la organización popular antagonista al poder oligárquico - que se ve ahora 
provista de antiguos y nuevos referentes discursivos radicales y plantea un reto insoslayable.

Más allá de este reto, que muchos conservadores prefirieron no enfrentar, la reforma jurídica del estado había sido conducida por la izquierda con respaldo de los militares, y del partido liberal que entre sus facciones incluía un influyente sector en respaldo de la reforma social. Si la articulación entre funcionarios públicos reformistas que visitaban el territorio o repartían justicia pública y comunidades demandantes acompañadas de abogados provistos de retóricas socialistas resultaban aterradoras, parecía más amenazante que estos intermediarios sean desplazados por el pueblo y este pase a primer plano. Velasco lo vio con claridad: se trataba de suspender las mediaciones jurídicas instaladas por la izquierda durante la reforma al tiempo que se mantiene levantado el llamado al pueblo, pues suspenderlo era inviable. Para suspender las constituciones que asentaban el carácter social del estado buscó respaldo del ejército en los 30, pero falló en ese intento. Lo que sí logró a mediados de los años cuarenta fue articular una contrareforma con respaldo de un inusitado pacto oligárquico interpartidista y del celebre FBI de Hoover.

Todo esto es esencial para discutir el intento de convertir la figura de Velasco Ibarra en la prueba de que existió un proceso comparable al del populismo clásico en el Ecuador. No nos sirve una comparación a nivel de presidencialismo, ni las figuras sobresalientes contienen los elementos sustantivos del proceso que tuvo su curso en distintas sociedades. Lo que es paradójico en el caso ecuatoriano es que el proceso de conflictividad sociopolítica y de reforma estatal, así como la emergencia de lo popular en representación política, jurídica y cultural, no estuvieron encabezadas por la forma caudillista. El líder, que la historiografía erradamente convierte en signo de la época, se forja en una disputa y representa el intento de clausurar esta vía popular; y, de forma estratégica, usa la vía popular para clausurarla, tal como lo hizo por ejemplo en 1946, y también en sus últimos gobiernos.

En el Ecuador hubo un proceso de transformación nacional-popular a signo y nivel como en Bolivia, México o en Argentina, pero sin el desarrollo de un caudillo de izquierda. De hecho, los partidos políticos en el Ecuador, lejos de debilitarse, 
se habían fortalecido hacia 1934: partido comunista, partido socialista, partido liberal. Es decir, toda la disputa se dio en el marco de la constitución de bloques de partidos. No desaparecieron los partidos para que surja un caudillo, sino que los partidos se transformaron desde adentro, como ocurrió con el liberalismo, también el surgimiento y despliegue de las izquierdas, y hasta el mismo partido clerical se transformó; también se conformaron nuevos bloques. ${ }^{1}$

Dentro de mi investigación, identifico el problema de lo nacional- popular en sucesivos ciclos históricos: el primero ciertamente fue el del radicalismo liberal, que más que un episodio fue una fuerza constituyente del estado (condición incluso para la expansión comercial); el segundo, el proceso contemporáneo al populismo clásico en las décadas de la crisis mundial e interguerras; y, el tercero, el giro antineoliberal de finales del siglo XX.

El debate sobre el populismo, sobre los métodos de articulación política populista, así como los estudios sobre retroceso o expansión democrática, sobre procesos redistributivos, entre otros, cobran sentido si los ponemos en diálogo con lo que la historiografía y la sociología histórica observan como ciclos de la revolución democrática. Esto es, la capacidad que puede tener una sociedad y su forma histórico-política para responder y desarrollarse ante coyunturas de tensión entre el capital monopólico y el campo político forjado en la historia republicana moderna.

Así, lo que evalúo en los ciclos históricos conectados que estudio son los procesos de reemergencia de la política popular instituyente, los procesos de reforma del Estado que le facultan para reconocer el sentido social de la propiedad y, por tanto, constituirse en un agente garante de inclusión y de tratamiento democrático de la desigualdad y la consecuente conflictividad social. En otras palabras: momentos 
en los cuales el Estado está constituido por una correlación de fuerzas que le dotan de relativa autonomía frente al capital para salvaguardar las razones políticas y las nociones de justicia viables, lo cual asociamos con una racionalidad republicana democrática de varias generaciones.

Volviendo un poco atrás como historiadora, pienso que el problema del populismo, o de lo nacional-popular, -o de este ciclo de transformación del apoderamiento social y transformación del Estado-, es su ubicación dentro de un proceso más largo que se llama 'el proceso de revoluciones democráticas'. Las revoluciones democráticas tienen también sub-ciclos y coyunturas dentro de la complejidad de pensar en el tiempo histórico. El primer ciclo de lo nacionalpopular ocurre en la formación de las repúblicas en un combate entre otro tipo de sujetos de clase, estamental y racial. Pero también surge otro combate, que me interesa mucho de manera particular y que los que estudian el populismo no abordan de manera directa, que permite ver la relación entre el ciclo republicano y un segundo ciclo que es el de los años treinta de la crisis mundial. A mí me interesa esa conexión que Gramsci hace entre el ciclo jacobino de lo nacional-popular y el ciclo en el que una tendencia socialista de lo nacional-popular o de la cuestión social se puede constituir en medio de una recia disputa contra la vía fascista o autoritaria de inclusión social durante la crisis mundial. En la historia de estos ciclos de la revolución como categoría histórica inscribo yo el tema del populismo.

P: En tu trabajo sobre la formación del Ministerio de Previsión Social y Trabajo ${ }^{2}$ en los años treinta, éste aparece como el resultado de una lucha política que logra incrustarse en el Estado. Éste es un ejemplo concreto de este ciclo que describes. ¿Podrías referirte sobre quiénes son los principales actores de este nuevo ciclo de conflictividad social? ¿quiénes protagonizaron esta acción colectiva? Por otro

2 Sobre este trabajo, revisar el texto de Valeria Coronel (2009) "Orígenes de una Democracia Corporativa: estrategias para la ciudadanización del campesinado indígena, partidos políticos y reforma territorial en Ecuador (1925-1944)", en Kigman, Eduardo (ed.) Historia social urbana: espacios y flujos (pp. 323-364) Quito: FLACSO/Ministerio de Cultura. 
lado, hablaste también de la renovación de la esfera pública que quizás corresponde más al trabajo que has explorado sobre modernismo, la vanguardia, la literatura popular, la prensa chica de los años $30 .{ }^{3}$ ¿Podrías describir los actores que estaban protagonizando esos dos espacios, tanto el campo de conflictividad política como el espacio de renovación de la esfera pública?

Valeria Coronel: Esa es una pregunta importante, porque pensar que de hecho hay una conexión entre la transformación de la esfera pública y de la organización política permite establecer puentes entre dos campos que siempre se ven de alguna manera separados. Los estudios sobre literatura abordan autores y evalúan textos, pero no ven en qué contexto de producción se produjeron esos textos; y el campo de la organización política pareciera que proviene directamente de la necesidad, del hambre, de la escasez, o de manuales políticos, sin plantearse que proviene, en gran parte, del modo en que se concibe el conflicto y que, además, tiene mucho que ver con un diálogo ideológico, intelectual, cultural.

Se supone, también, que el campo de la movilización popular, si acaso viene de alguna cultura, se origina de una cultura arcaica, o de una cultura-cultural, y no de una cultura-política con genealogías cercanas a las grandes tradiciones políticas que comparten las sociedades cosmopolitas, como es la latinoamericana desde inicios de la modernidad. Pareciera que el campo de lo intelectual se conecta a nivel global en el campo de las ideas cuando, en realidad, su cosmopolitismo está arraigado en instituciones sociales como la justicia, la visualidad, la noción de autoridad. Sin tomar aquello en cuenta no se puede ver el vínculo entre procesos organizativos y lenguajes políticos, y no logramos entender cómo los actores consideran qué es lo qué está en disputa en determinada coyuntura, pues no leemos su ejercicio de interpretación como un uso de categorías políticas. Por ejemplo, ¿por qué se produce la imagen del montubio en Ecuador? El modo en que entra en

3 Se recomienda revisar el texto Coronel, Valeria (2010) "La Fragua de la Voz. Cartas sobre revolución, subjetividad y cultura nacional popular", en Alemán, Gabriela y Valeria Coronel (eds.). Vienen ganas de cambiar el tiempo (pp. 381-490), Quito: Distrito Metropolitano de Quito. 
escena la imagen del montubio es clave para entender procesos de movilización y también la renovación del ámbito intelectual y de la imprenta.

Yo he tratado de conectar esas dos esferas y podría decir que actualmente sigo trabajando obsesivamente los mismos temas, pero descubriendo nuevas facetas. Los actores y los intelectuales que son claves en el ciclo de reforma nacional-popular de la crisis -durante los años veinte, treinta y cuarenta - se forman en dos ámbitos producidos dentro de la hegemonía liberal: provienen tanto de la imprenta liberal, como de la organización del partido democrático liberal, que es el partido popular durante mucho tiempo. En estos dos círculos, el organizativo del partido liberal y el intelectual del partido liberal, hay un proceso de renovación, cuestionamiento y fractura interna.

Pensemos en el origen del pensamiento socialista y su impacto. ¿Cómo puede uno entender que un periódico periférico inventado por unos jóvenes dentro de una organización pequeña, pero dentro de una confederación política -como por ejemplo fue el periódico Bandera Roja-, tuviera capacidad de generar una crítica a la unidad del partido liberal y una confrontación al nivel de Guayaquil 1922? En este periódico participaron jóvenes que se reunían en un cuarto de la 'Sociedad de cacahueros “Tomás Briones”, que era parte de la Confederación Obrera del Guayas. Se identificaron como los fundadores de la Federación Regional de Trabajadores del Ecuador en Guayaquil, pero movilizaron por dentro y por fuera de una organización histórica. Ellos proponen una tesis: el partido liberal ya no es el partido de Alfaro. No solo porque Alfaro murió, sino porque hay contradicción de intereses: ya no es creíble - arguyen - la alianza entre el pueblo, la cholada liberal, y los burgueses barrigudos de la banca. Además, afirman, los intelectuales de la democracia liberal se escondieron cuando fueron invocados. El pueblo liberal y la burguesía liberal ya no están del mismo lado. Hay una tensión dentro del partido que hay que afrontar, y ellos colocan el concepto de proletariado en el periódico Bandera Roja bajo un nombre propio: 'Yo Cholo'. No fue que la influencia bolchevique les hizo olvidar de donde venían, sino precisamente lo contrario: insertaron en el discurso de justicia liberal y en sus organizaciones el concepto de raza y proletariado. No utilizaban el 
vocablo 'raza' pero insertaron el concepto de 'el cholo', 'el montubio'. Al insertar esa idea dentro del pensamiento liberal, hacen que el pensamiento liberal se remueva al decir 'el campesino, el cholo, no se siente ya respaldado por el burgués barrigudo que supuestamente nos representa a todos. ¡Ya no es cierto! ¡El partido es de ustedes o es de nosotros!'

De este modo, la renovación política, el pensamiento socialista y la organización atenta a problemas clasistas se da simultáneamente en aquellos espacios cercanos a la instrucción publica, a la cultura, a la noticia política de la prensa liberal y en aquellos que se construyeron como el ámbito democrático de la sociedad civil afín al partido liberal: en primera instancia al interior, en antagonismo desde el interior, para también luego en otros niveles de confrontación. Lo que no podemos pensar es que la renovación de los años veinte y treinta se da en el vacío, o únicamente debido a la necesidad, pues tiene lugar en la experiencia de la contradicción, en el marco de la hegemonía democrática del Partido Liberal. Estos actores insertaron un dispositivo de transformación revolucionaria dentro del partido político y usaron el lenguaje político. Empezaron por combinar categorías como 'pueblo', 'raza y 'proletariado', combinaron categorías como 'democracia' con categorías como 'revolución'. Empezaron a hablar de 'ciudadanía', que es una propuesta importantísima desde el triunfo de la revolución liberal (y aún antes) para la movilización; y esta categoría obviamente el Partido Comunista de la Unión Soviética no empleaba. En el Ecuador, el partido comunista sí emplea y define el concepto de ciudadanía, añadiendo que, para que esta sea tal y la dominación feudal sea vencida, la ciudadanía tiene que ser económica.

Entonces yo diría, sin darte nombres porque estos ya los conocemos todos, que las organizaciones fundamentales de la reforma de la crisis son las organizaciones de izquierda: socialismo, liberalismo radical y comunismo. Pero estas tres no las podemos ver como fundación desde cero de nuevas corrientes, pues provienen de la disputa democrática al interior del partido liberal y de hecho transforman esta disputa. Este es el caso del bloque socialista dentro de las Fuerzas Armadas, de los universitarios de Quito - que son gente que estudia filosofía y sociología en la 
Universidad Central del Ecuador - que forman núcleos intelectuales que usan la prensa liberal para intentar conectarse con un sector descontento de la organización obrera y tratar de dar un salto dentro de la organización política existente de la que luego surgirá una izquierda.

Este es el escenario con el que se enfrenta la crisis de 1925 - y esto es clave no porque yo sea historiadora y mi formación disciplinar me haga retrotraerme al pasado, sino porque no se puede explicar lo que pasa entre 1925 y 1934 y en adelante sin entender que la fuerza de la reforma viene espoleada por la fuerza que tenía la propia organización política en el Ecuador. Había ya de hecho nociones de derechos, de ciudadanía, y había la idea de que cuál era el partido popular. Entonces, denunciar los límites de la Revolución Liberal permitió construir un nuevo ciclo y conectar con corporaciones - como el ejército, la universidad, la educación pública, la salud -, con la disputa entre comunidades y haciendas, que ya se había asociado una vez con el Partido Liberal, y que esperaba su momento de ser abordada nuevamente. Crear el Ministerio de Previsión Social (1926) no fue crear instituciones sobre la nada: fue retomar el discurso con el que se abolió la esclavitud, según el cual hay formas de propiedad que atentan contra la república y la soberanía popular; fue retomar el discurso de la Ley de Manos Muertas, la crítica a la servidumbre del concertaje, el discurso de los deberes garantistas del Estado; y fue hacerlo en el tiempo de la cuestión social, en el que se vivió en el Ecuador como un segundo ciclo de la revolución. Al interior del liberalismo, en un punto inicial 1923-1926, se debatió ya la deriva oligárquica y violenta que había amordazado al partido. Este proceso político, entre otros que merecen detenida atención, permitió revitalizar cierta genealogía democrática e institucionalizar este organismo que tiene su propia identidad en la historia mundial de los Estados de Bienestar Social.

Joaquín Gallegos Lara, que viene de la prensa liberal, su padre y su tío fueron claves en el desarrollo del proyecto de crear una crítica contra el hispanismo, contra la noción de economía moral paternalista de los católicos, y una crítica al clericalismo. Los Gallegos del Campo crearon círculos de lectura dentro del partido para dar clases populares. Vienen de leer a Montalvo, a los peruanos Gonzales 
Prada y Valdelomar, al modernismo liberal ecuatoriano y cubano, a Mariátegui. La prensa liberal había construido preguntas que tuvieron que responderse mediante sucesivos ciclos de ruptura y recreación de la forma artística. Una de esas rupturas fue la proclama de la libertad de la forma, cercana a la revolución anticlerical; otra fue la entrada de la voz popular como voz moderna en la literatura

P: Queda claro que, en el momento histórico, que describes hay una renovación del ciclo de la revolución democrática que nos permitiría ver en el Ecuador algo como lo que Gramsci hace entre el ciclo jacobino y el ciclo socialista. En algunas intervenciones has señalado el carácter de estas luchas que, me parece, dicen de la particular forma de modernidad en América Latina. Esto quizá ha sido más elaborado en el caso de otros países (pensemos en el trabajo de James Sanders sobre republicanismo y liberalismo popular en Colombia ${ }^{4}$, o de la acumulación de luchas que se consuman en la revolución boliviana de 1952 como plantea Gotkowitz $^{5}$ ) y aquí en el Ecuador tu trabajo está abriendo esta línea. ¿Cuáles serían las particularidades del republicanismo latinoamericano y su originalidad en contraste con otras experiencias de republicanismo, especialmente el republicanismo europeo?

Valeria Coronel: Yo no diría que hay un solo republicanismo europeo, ni un solo republicanismo latinoamericano, aunque sí es verdad que en América Latina hay una serie de procesos que tienen un signo específico. Aquí habría que remontarse a los debates clásicos de sociología histórica, pues el contraste fundamental es entre el surgimiento de estados modernos, o repúblicas, en los cuales hay una derrota absoluta del campesinado, y otras repúblicas en donde hay una articulación política, 
coyuntural y de formación de bloques interclasistas. ${ }^{6}$ Entonces hay una trayectoria, como la inglesa, marcada por la derrota del campesinado y su proletarización. En dicha historia, la derrota del campesinado es el origen de la propiedad privada como forma dominante.

En América Latina, hay países en los que se derrotó el campesinado; y desde allí empezó una modernización desde arriba. Hay países, por otro lado, donde tal modernización desde arriba ha sido inviable, no solo por la precariedad de las elites, sino también porque existe una trayectoria de bienes colectivos y bienes públicos que ha logrado sostener cierta existencia política. Esto no significa que no hay concentración de riqueza o que no predomina el capitalismo y se subordina incluso a los mundos campesinos; pero sí significa que la forma de la república no se funda sobre la desposesión y la propiedad privada, sino que debe integrar a nivel orgánico, aunque contradictoriamente, mecanismos de reconocimiento y de garantía para la existencia material y política de los bienes comunes, así como nociones de 'función social' de la propiedad. Esto supone que hay ciertos dispositivos democráticos en tales sociedades, aunque estos no sean precisamente la coordinación de los individuos votantes sino más bien el deber de garantizar la expansión de los derechos y contener las dominaciones que los impiden.

Las comunidades son redes de parentesco interclasista complejas que atraviesan distintos estratos sociales. En estas sociedades, los sujetos políticos dieron mucho peso a la negociación de fueros y de derechos; lograron asumir lenguajes políticos de tipo republicano para defender bienes colectivos, bienes de distintos estamentos sociales; matizaron la condición colonial y se volvieron agentes de conflicto y negociación. Así se marco toda la trayectoria de la esfera política desde los partidos hasta las formas estatales, desde la monarquía hasta la forma contemporánea. No siempre de manera democrática, pero definitivamente fueron actores que no podían ser soslayados. Entonces, el modo de construir el poder en las repúblicas en las que no son derrotados los campesinos (por decir de alguna forma 
a lo colectivo), donde son subsumidos, pero también capaces de lograr acumulación política, es un modo que requiere el desarrollo relativamente autónomo del trabajo político. Hay una tensión entre poderes que debe lograr traducirse en el estado.

Así, los republicanismos tuvieron que negociar con la propiedad, pero también con el poder de lo popular, porque, al mismo tiempo que subordinan y sobre-explotan las comunidades campesinas, éstas son fuente de una articulación de lo popular que es relativamente autónoma. Tal como lo ha observado ZavaletaMercado y toda la transición del socialismo andino, hay sobreexplotación pero también hay cierta autonomía. ${ }^{7}$ Ahí hay una clave teórica: uno puede ver más fina y exténsamente cómo van condicionando al poder político las articulaciones de lo popular, clases medias y las pequeñas burguesías, e incluso ciertas burguesías antiimperialistas. Hay que estudiar cómo se conforman estos bloques democráticos y, en esos casos, el republicanismo incluye ciertos ingredientes que no son iguales al liberalismo que se centra solo en la propiedad privada. Se debe reconocer, en estas repúblicas, la coexistencia problemática y catastrófica de la propiedad que tiende a constituir el vinculo oligárquico junto con otras formas de propiedad reconocidas por su función social y su condición como prerrequisito de la libertad y, por tanto, de los derechos fundamentales entre los miembros de una nación.

\section{P: ¿Identificas entonces una forma particular en el republicanismo en América} Latina?

Valeria Coronel: En América Latina, por características que están bien explicadas por la sociología en los años sesenta, las élites no necesariamente son capaces de construir estados modernos, derechas modernas o ceder algunas de sus ambiciones. Por el contrario, son regionalistas, parásitas, y no logran sumar políticamente lo que ya sumaron económicamente.

7 Ver Zavaleta Mercado, René ([1984]2013). "Lo nacional-popular en Bolivia", en Obra Completa. Tomo II: Ensayos 1975-1984, La Paz: Plural; Zavaleta Mercado, René (1983) "El Estado en América Latina" en Zavaleta, René / Luis Tapia (ed.), La autodeterminación de las masas. (pp. 321-355), Buenos Aires: CLACSO 
Entonces, las clases, que solo pueden construir fuerza a través de articularse en un sujeto colectivo, pueden dar forma a lo público e intentar sostener el estado de una forma que las oligarquías depredadoras no suelen hacer. Estas últimas utilizan el estado, lo obligan a rendirse y, por tanto, no garantizan su reproducción: la oligarquía tiende a destruir el estado, y, por tanto, siempre se renuevan los ciclos democráticos.

Una de las características en América latina es el largo aliento del republicanismo democrático que es, al mismo tiempo, interesante y problemático. Esto porque el republicanismo democrático permite la coexistencia entre la función social de la propiedad, o el bien común, y la propiedad privada, que es clave para la producción o acumulación capitalista. Éstas coexisten permanente y no hay una 'derrota' de una de las clases y luego un avance hacia un proceso democrático o socialista, sino que hay ciclos: en condiciones democráticas, el capital se reproduce y consolida. Luego, las oligarquías, apegadas a un poder transnacional que logra intervenir, se hacen con el estado, pero, como no son capaces de sostenerlo a largo plazo, puesto que no son realmente una derecha moderna, los ciclos de acumulación política popular y democrática vuelven.

Ángel Felicísimo Rojas decía, refiriéndose al Ecuador, 'las constituciones son capas geológicas de la revolución y la contrarrevolución'. La coexistencia de estos dos ciclos es una característica latinoamericana. En China, derrotaron a las clases transnacionales, en Inglaterra derrotaron al campesinado, en Francia la burguesía derrotó a todos sus adversarios, pero en América latina tenemos ciclos híper-revolucionarios y ciclos híper-contrarrevolucionarios. Esa sí podría ser una característica latinoamericana.

P: En el capítulo que escribes para el libro A Contracorriente, ${ }^{8}$ sostienes que la crítica que en los años sesenta hicieron los sociólogos marxistas en el Ecuador

8 Coronel, Valeria (2018) "Cómo se volvió invisible el populismo de izquierda en el Ecuador: elementos para reevaluar la relación entre izquierda, populismo y democracia”, En Cadahia, Luciana, Valeria Coronel y Franklin Ramírez (2018). A contracorriente. Materiales para una lectura renovada del populismo. (pp. 65-77) La Paz: Vicepresidencia del Estado Plurinacional de Bolivia 
es miope ante la posibilidad de conectar esa reactivación de los ciclos de la revolución democrática con la lucha política de la izquierda en general. Hasta cierto punto el republicanismo popular aparece desconectado de la lucha de la izquierda ecuatoriana. ¿Podrías ampliar un poco más es esta idea?

Valeria Coronel: En los años sesenta y setenta se produjo uno de los momentos de institucionalización académica y de construcción de un pensamiento profesional y crítico en y desde América Latina, que es un legado fundamental del presente. Pero la experiencia de esta generación es de ciclos muy cortos y muy violentos. La renovación de la revolución en los años sesenta fue fuerte y poderosa; y hubiera sido muy interesante que prospere, pues seguramente hubieran podido conectar con tradiciones de revolución anteriores. Sin embargo, no fue así puesto que inmediatamente vinieron los golpes de estado en toda América Latina, la violencia, la reacción neoliberal salvaje. Se trata de una generación que tuvo poca experiencia en el poder, tuvo un horizonte de transformación que hubiera sido interesantísimo, pero no tuvo experiencia de gobierno.

Consecuentemente, hay varias razones por las cuales ellos desconfían de los ciclos políticos anteriores, en los que se despliegan proyectos interclasistas/ populares, antioligárquicos, en el poder. Primero por su falta de experiencia en participar de la hegemonía, porque cuando empezaron a participar tuvieron que enfrentar el golpe transnacional. Claro, una cosa es hacer hegemonía de izquierda en el contexto de la guerra internacional, y otra cosa es querer hacer hegemonía de izquierda en el contexto de los orígenes del neoliberalismo, en la ola del capital monopólico internacional después de que la Guerra Fría preparó el terreno para la reconstrucción del capitalismo de manera monopólica.

Pero, la otra razón es que ellos evalúan la promesa democrática, y la relación entre modernización económica y democracia, no en base a la lectura de lo que en los años treinta se planteó sobre el papel del estado interventor en la economía que garantizaría condiciones de autonomía de las poblaciones para que puedan ejercer sus derechos políticos y vayan orientando al camino del bien común. Ellos 
conciben la relación entre modernización económica y democracia en base al proyecto de fomento de la Guerra Fría, a la promesa del equilibrio entre democracia y progreso, y lograron ver claramente el carácter estructural de la dependencia. También observaron que el proyecto del Partido Comunista, que era la lucha contra el fascismo y el feudalismo, no había asumido que lo arcaico era funcional al desarrollo del capitalismo a nivel productivo.

P: Planteando la existencia de formas de trabajo subsidiario de la explotación en términos capitalistas y su composición global...

Valeria Coronel: Exacto, ellos sostenían que no había dualismo sino heterogeneidad estructural - lo que es una gran observación. Hay una autocrítica interesante en esa misma generación que se articula con el pensamiento marxista andino al plantear que los dispositivos sociales que subsidian al capitalismo, es decir, aquellos de la heterogeneidad estructural, no son solo espacios funcionales económicamente, también son espacios de identificación política popular, de construcción de poder, y de lo nacional-popular. La comuna rural no sólo subsidia el capitalismo, sino que también constituye módulos de la constitución de un capital político relativamente autónomo, en el que lo popular se organiza como fuerza que sobrevive. Hablar en categorías de los setenta es complejo, pero es claro que, si el actor tiene que sobrevivir para subsidiar, al mismo tiempo esas articulaciones económicas de subsidio son articulaciones de identidad política, de formación de una lucha popular. Las clases medias de las crisis pueden proletarizarse y articularse con estas organizaciones populares. Las articulaciones entre clases golpeadas por la dependencia y el colonialismo pueden dar forma a un horizonte de modernidad y una forma política que no será ya simple instrumento de la acumulación capitalista como piensan los escépticos.

P: Uno de los puntos interesantes es que esta dificultad de reconectar con el republicanismo popular, con esta tradición de articulaciones de los años 
veinte y treinta, es precisamente lo que impide a los teóricos marxistas de esta generación considerar el populismo como una lógica de articulación política que no es simplemente discursiva, sino que históricamente responde a un acumulado de luchas. Así, uno de los aportes de esta idea de pensar el republicanismo popular, y los ciclos de la revolución democrática, ayuda a complejizar el debate y quizás mirar en otra dirección para poder ver lo que en los años setenta no se vio.

Valeria Coronel: Claro. Se debería hacer una sociología política, no solamente en el sentido electoral y movilización del voto, sino ver el nivel organizativo que es mucho más interesante. Además habría que ver qué tipo de lenguaje porta la gente y por qué conecta finalmente con la interpelación. El estudio de Daniel James sobre el peronismo en Argentina es interesante en ese sentido. ${ }^{9}$ James observa claramente cómo un funcionario estatal, como era Perón, levanta el concepto de ciudadanía del Partido Radical [Unión Cívica Radical- UCR], que era el partido que tenía más cultura popular, y le da un nuevo sentido unido a la cuestión social. Así, conecta economía, estado y ciudadanía y articula a las organizaciones de izquierda y las potencia. Hubo organizaciones que no quisieron unirse y quedaron fuera debido a que, para las izquierdas de los años treinta, era claro que había que reformar.

P: Incluso obligó a que estas organizaciones de izquierda se renovaran.

Valeria Coronel: Exactamente, y les dio poder, pues antes eran periféricas. Había un partido anarquista, comunista y socialista, pero la industria argentina, a pesar de ser poderosa y contar con mucho dinero, trataba a los trabajadores como se hacía en los lugares más precarios del continente. Esa conexión entre reforma estatal, organización popular y tradiciones republicanas democráticas es clave para pensar el populismo, pero hay que observar los tres niveles. 
$P:$ ¿De qué modo este análisis sobre la historiografía nacional también abre otro tipo de vías de investigación tanto en el ámbito historiográfico así como de reflexión teórica?

Valeria Coronel: Me parece clave analizar el presente. La coyuntura contemporánea es un momento de acumulación histórica de largo aliento. En los ciclos de crisis se acumulan todos los ciclos históricos. No podemos evaluar lo que está pasando hoy en el Ecuador recorriendo solamente cinco años atrás. No digo que tenemos que remontar a hacer una enciclopedia de la historia ecuatoriana, sino ver cómo se acumulan ciclos de reforma tecnocrática del estado hoy, cómo se acumulan ciclos de acomodamiento de las izquierdas existentes en los últimos veinte años, y por qué hoy actúan como actúan. Es decir, hay que conectar varias temporalidades en el presente.

Por otro lado, hay que hacer sociología política, no quedarnos con la definición de la relación entre caudillo y masa, sino observar qué paso con la organización popular, cómo usaron el derecho. ¿Hubo una activación de la conflictividad por otros medios? ¿Cómo la reforma del estado generó instrumentos para la conflictividad social de los años noventa de la movilización en las calles y la crítica a la partidocracia? El ciclo de combate cambió en la década pasada y generó otros instrumentos legales, pero ¿cómo avanzó la conflictividad? ¿Avanzó o se bloqueó la conflictividad? ¿Hubo medios para expresar el descontento colectivo y otra forma de denominación? Yo creo que estas preguntas se deben hacer sobre el período de Rafael Correa; es decir, sí, sabemos que hubo procesos redistributivos, que el estado se presentó como un estado reparador en un clásico sentido republicano democrático y nacional popular. El proceso constituyente se orientaba a traducir en términos políticos y jurídicos el combate contra el neoliberalismo y contra la partidocracia que impedía el paso de las demandas hacia el estado y que había bloqueado las rutas democráticas entre la sociedad civil y el estado. La gente percibió y cuestionó ese bloqueo. Esto estuvo en manos tanto del movimiento indígena, como del movimiento constituyente. ¿Qué pasó en los diez 
años de Correa? Se rompieron esos partidos-diques por un tiempo, pero ¿cuáles fueron los mecanismos de organización política y las herramientas institucionales que se desarrollaron y pusieron a disposición alternativamente para que la sociedad pudiera transmitir sus demandas y al mismo tiempo mantener nutrida la forma estatal que ayudó a crear? ¿Qué ruta podría retomar la sociedad hoy para reactivar la forma estatal que subyace en medio de la transición empeñada en desmantelarla? $\mathrm{Y}$, si no encuentra esta ruta, ¿hablamos de caducidad? ¿O es posible pensar en la potencial regeneración del legado político de varios ciclos en una nueva contienda instituyente? 


\section{Referencias}

Coronel, Valencia (2009) 'Orígenes de una Democracia Corporativa: estrategias para la ciudadanización del campesinado indígena, partidos políticos y reforma territorial en Ecuador (1925-1944)', en Kigman, Eduardo (ed.) Historia social urbana: espacios y flujos (pp. 323-364) Quito: FLACSO/ Ministerio de Cultura.

Coronel, Valeria (2010) 'La Fragua de la Voz. Cartas sobre revolución, subjetividad y cultura nacional popular', en Alemán, Gabriela y Valeria Coronel (eds.). Vienen ganas de cambiar el tiempo (pp. 381-490), Quito: Distrito Metropolitano de Quito

Coronel, Valeria (2016) 'La revolución gloriosa: una relectura desde la estrategia de la hegemonía de la izquierda de entreguerras'. En Cabrera, Santiago (coord.). La Gloriosa: la revolución que no fue. Quito: Corporación Editora Nacional: Universidad Andina Simón Bolívar, Sede Ecuador.

Coronel, Valeria (2018) 'Cómo se volvió invisible el populismo de izquierda en el Ecuador: elementos para reevaluar la relación entre izquierda, populismo y democracia', En Cadahia, Luciana, Valeria Coronel y Franklin Ramírez (2018). A contracorriente. Materiales para una lectura renovada del populismo. (pp. 65-77) La Paz: Vicepresidencia del Estado Plurinacional de Bolivia

Coronel, Valeria (2018) 'Izquierdas, sindicatos y militares en el bloque de izquierdas del Ecuador de interguerras (1925-1945)', en Camarero, Hernán y Marcelo Mangiantini (eds.) El movimiento obrero y las izquierdas en América Latina. Experiencias de lucha, inserción y organización (pp. 195-215). Chapel Hill: University of North Carolina Press

Gotkowitz, Laura (2011) La revolución antes de la revolución. Luchas indígenas por tierra y justicia en Bolivia 1880-1952. La Paz: Plural

James, Daniel (2010) Resistencia e integración: el peronismo y la clase trabajadora argentina. Buenos Aires: Siglo XXI 
Moore, Barrington ([1966]1973) Los orígenes sociales de la dictadura y de la democracia. Barcelona: Península

Sanders, James E. (2009) 'Ciudadanos de un pueblo libre: liberalismo popular y raza en suroccidente de Colombia en el siglo XIX', Historia Crítica 38, 172-203

Sanders, James E. (2011) 'The Vanguard of the Atlantic World: Contesting Modernity in Nineteenth century Latin America', Latin American Research Review 46(2), 104-127

Skocpol, Theda ([1979]1984] Los estados y las revoluciones sociales. México: FCE Zavaleta Mercado, René ([1984]2013). 'Lo nacional-popular en Bolivia', en Obra Completa. Tomo II: Ensayos 1975-1984, La Paz: Plural

Zavaleta Mercado, René (1983) 'El Estado en América Latina' en Zavaleta, René / Luis Tapia (ed.), La autodeterminación de las masas. (pp. 321-355), Buenos Aires: CLACSO 